\title{
Physiological rules for the heart, lungs and other pressure-based organs
}

\author{
Aaron R. Casha ${ }^{1,2}$, Liberato Camilleri ${ }^{3}$, Alexander Manché ${ }^{2}$, Ruben Gatt ${ }^{4}$, Marilyn Gauci ${ }^{5}$, Marie-Therese \\ Camilleri-Podesta ${ }^{1}$, Joseph N. Grima ${ }^{4}$, Marco Scarci ${ }^{6}$, Stanley Chetcuti ${ }^{7}$
}

${ }^{1}$ Biomedical Sciences, Faculty of Medicine, University of Malta, Msida, Malta; ${ }^{2}$ Department of Cardiac Services, Mater Dei Hospital, Msida, Malta; ${ }^{3}$ Department of Statistics and Operational Research, University of Malta, Msida, Malta; ${ }^{4}$ Metamaterials Unit, Faculty of Science, University of Malta, Msida, Malta; ${ }^{5}$ Department of Anaesthesia, Mater Dei Hospital, Msida, Malta; ${ }^{6}$ Department of Thoracic Surgery, University College London Hospital, London, UK; ${ }^{7}$ Cardiovascular Center, University of Michigan, Ann Arbor, Michigan, USA

Contributions: (I) Conception and design: AR Casha; (II) Administrative support: AR Casha; (III) Provision of study materials or patients: AR Casha; (IV) Collection and assembly of data: AR Casha; (V) Data analysis and interpretation: AR Casha, L Camilleri; (VI) Manuscript writing: All authors; (VII) Final approval of manuscript: All authors.

Correspondence to: Aaron R. Casha, MD, PhD. Medical School, University of Malta, Mater Dei Hospital, Msida, Malta. Email: aaron.casha@um.edu.mt; Marco Scarci, MD. Department of Thoracic Surgery, University College London Hospital, London, UK. Email: marco.scarci@nhs.net.

Background: The adherence of the heart to physical laws, such as Laplace's Law, may act as a measure of the organ's relative efficiency. Allometric relationships were investigated to assess the heart's efficiency concerning end-diastolic and end-systolic volumes, cardiac pressurization energy, cardiac output and mass.

Methods: Data to generate allometric relationships was obtained using a literature search, identifying heart and lung data across different mammalian and bird species. Statistical analysis was carried out using ordinary least squares (OLS) estimation.

Results: Near isometric relationships exist between body mass and seven parameters indicating no "efficiency of size" with scaling of the heart, and size-matching of the heart to the lungs and whole body. Even though there was equal efficiency in pressurization energy generation, cardiac output was maximally efficient in small mammals $<10 \mathrm{~kg}$ and birds; the human heart reached only $71 \%$ efficiency. This loss in cardiac efficiency with increasing body mass can be explained by the aortic cross-section that scales following the three-quarter allometry law, compared to end-systolic and end-diastolic volumes that scale isometrically. The heart is therefore throttled by a relatively small aorta at large body size.

Conclusions: Mammalian and avian hearts operate at similar efficiencies, demonstrating a high degree of symmorphosis, however cardiac output efficiency decreases in larger animals due to a relatively negative aortic cross-section allometry. This work has a myriad of potential applications including explaining cardiac dysfunction in athletes, patient-prosthesis mismatch in aortic valve replacement and why heavy exercise is associated with a worse prognosis than mild or moderate exercise.

Keywords: Physiology; allometry; biomechanics; symmorphosis

Submitted May 01, 2017. Accepted for publication Sep 15, 2017.

doi: $10.21037 /$ jtd.2017.09.86

View this article at: http://dx.doi.org/10.21037/jtd.2017.09.86

\section{Introduction}

The structure of an organ system is matched to its functionality according to Taylor and Weibel's theory of symmorphosis (1). This principle was defined as a biological system with economy of design and regulation at all levels. Since this principle is related to natural selection, it has been suggested that evolution may have played a major part in the mechanism of development of symmorphosis (2). As Calder had argued, symmorphosis can provide a theoretical 
basis for scaling relationships (3). Therefore allometry can be related to the pressures of natural selection, with optimization of efficiency of function leading to survival of the fittest, and the degree of symmorphosis can be tested by the degree of adherence to predicted allometric relationships (4).

In allometry, the relationship between two measured variables is governed by a power law. The classical allometric equation was developed by Otto Snell in 1892 (5):

$$
Y=K M^{a}
$$

where $Y$ is the dependent variable, $M$ is the body mass, $\alpha$ is the scaling exponent and $k$ is a constant. In logarithmic form this power law takes the form:

$$
\log Y=a \log M+\log k
$$

However variables other than body mass are used in allometry $(6,7)$, and the current definition of allometry has been widened to include the study of how all biological processes scale with each other (8). Depending on the magnitude and sign of $\alpha$, the allometry may be classified as positive allometry $(\alpha>1)$, negative allometry $(\alpha<1)$ and zero allometry $(\alpha=0)$. In the special case where $\alpha=1$, the dependent variable becomes directly proportional with body mass, and in such cases it is classified as isometry. Furthermore, zero allometry signifies that the parameter under investigation is independent of the body mass.

Certain physical laws govern physical processes, and biological processes must conform to these laws for the purpose of economy of function. Allometry can be affected by evolutionary pressures but may also be determined by physical constraints (9). As a result of the efficiency of the evolutionary process, organs that are subjected to similar conditions like distending pressure, as in classical mechanical pressure vessels, should scale similarly. If different animals all reach a similar level of efficiency in organ function as dictated by physical laws, then this would be proof of the concept of symmorphosis in scaling. It is suggested that a strict allometric relationship, adhering strictly to pressure vessel laws, would indicate that various species, have produced pressure-based or hollow organ systems all with very similar degrees of efficiency, using the biological building blocks available.

Despite the extensive body of literature discussing allometry $(10,11)$, as well as the well-established concept that various organs in the body could behave as pressure vessels $(12,13)$, no attempt has been made as yet to study how biological pressure vessels scale up within a population and across species, and whether the allometry of different organs within a genetically controlled allometry space conforms with that expected by classical pressure vessel theory $(14,15)$. This work aims to address this lacuna.

This work will attempt to show that for optimal functionality, pressure-based hollow organs, which in this work are being considered as pressure vessels, follow seven physiological rules of isometry when they scale in size. It is proposed that the mass of the organ is isometrically proportional to its volume of contents, as is the generation and release of its pressurization energy (the product of pressure and volume), and that isometry exists between masses of pressure vessels in the same body, with this isometry also extending to the relationship between the mass of pressure vessels within the body and mass of the body itself, as well as the thickness/radius ratio of organs (Laplace's law) across different species.

\section{Methods}

The physics of pressure vessels predicts isometric scaling relationships in pressure vessels. Our hypothesis is that hollow organs behave as biological pressure vessels. In order to validate the concept of isometry in pressure-based organs, a systematic literature search was performed. A search was performed in the Medline and Embase databases for original English-language publications. An extensive search strategy using a combination of subject headings ("pressure vessel”, "allometry", "isometry", "Laplace”, "heart", "lung", "bladder", "aorta") was constructed to find articles with animal data reporting cardiac and pulmonary physiological measurements including body mass, organ mass, organ dimensions, volume of contents, pressure and output measurements.

\section{Statistics}

Since the power law $Y=k M^{\alpha}$ can be linearized then the slope $\alpha$ of the regression line: $\log Y=\alpha \log M+\log k$, represents the allometry. Statistical analysis was carried out using ordinary least squares (OLS) estimation. OLS estimates $\alpha$ by minimizing the sum of squared differences between each predicted and actual values of $Y$. The statistic $t$ was used to determine whether the allometry value $\alpha$ differed significantly from 1 . This was calculated by dividing the difference between the predicted value â and its notional value $\alpha=1$ by the standard error of â: 


$$
t=\frac{\hat{\alpha}-1}{\operatorname{se}(\hat{\alpha})}
$$

Given that the statistic $t$ has a $t$-distribution with $(n-2)$ degrees of freedom, where $n$ is the sample size, it was possible to test the null hypothesis, $\left(H_{0}: \alpha=1\right)$, against the alternative hypothesis, $\left(H_{1}: \alpha \neq 1\right)$. Assuming a two-tailed test, the $\mathrm{P}$ value is the area of the critical regions at the tails of the $t$-distribution beyond the values $\pm t$. The null hypothesis was accepted if the $\mathrm{P}$ value exceeded 0.05 . The $95 \%$ confidence interval (CI) for the allometry $\alpha$ was also calculated. When the $95 \%$ confidence intervals included the value one, this indicated that the actual allometry did not differ significantly from 1. Pearson's correlation coefficient was used to assess the strength of the linear relationship between the variables $Y$ and $M$. Statistics were performed using both IBM SPSS software (Armonk, New York, USA) and Excel software (Microsoft Corp., Redmond, Washington, USA).

\section{Results}

Six data sources were identified $(12,16-20)$ and these datasets were used to generate allometric relationships. There is a near-isometric relationship between the parameters tested and masses of various organs such as the heart, lungs and bladder of various animals including humans; as shown in Figures 1,2 and Table 1. These relationships may be summarized into seven Rules, based on pressure vessel physics as follows:

Rule 1. Isometry between radius and wall thickness (Laplace's Law);

Rule 2. Isometry between pressure vessel mass and surface area (pressure-based organs are shells);

Rule 3. Isometry between pressure vessels in the same body (pressure-based organs are matched in size);

Rule 4. Isometry between body mass and pressure vessel mass (the body effectively scales as a pressure vessel);

Rule 5. Isometry between pressure vessel mass and volume of contents (indicating that there is no "efficiency of size" for mass in pressure-based organs);

Rule 6. Isometry between body mass or pressure vessel mass and pressurization energy, i.e., the product of pressure and volume (equal efficiency in generating energy);
Rule 7. Isometry between body mass or pressure vessel mass and energy output (equal efficiency in releasing energy).

\section{Discussion}

\section{Square-cube law}

Isometric scaling or isometry occurs when changes in size does not lead to changes in proportion. Isometry follows a square-cube law, a mathematical principle first described by Galilei in 1638 (21), that describes how any object undergoing a proportional change in size would have a resultant surface area that sizes as the square of the scaling factor; whilst the volume would be proportional to the cube of the scaling factor. This has biological implications, especially in allometry as the volume increases much more rapidly than the surface area.

\section{Physiological rules pressure-based organs}

The hypothesis of hollow organs behaving as biological pressure vessels explored here differs from previous explanations, including tissue density or indexing to weight reported by Crosfill (17) that divided mammals into different functional categories. In view of this, the rules derived in this study are discussed in detail below, with Rule 1 simply being Laplace's Law, which describes wall tension in pressure vessels.

The mass of pressure-based organs (e.g., lung) is isometrically related to its physical dimensions in particular to its surface area (Rule 2). Similarly the diffusing capacity of the lungs for oxygen $\left(\mathrm{DLO}_{2}\right)$ is proportionally related to the mass of the body with a scaling component of 0.99 (22). This isometric relation derives from Rule 2 above since diffusion is area dependent.

Rule 3 states that the masses of pressure-based organ are matched, and Rule 4 extends this to the whole body mass, such that the whole body effectively behaves as a pressure vessel, indicating symmorphosis. Some physiological processes are more efficient when handled by a pressure based process e.g., ventilation is more efficient in mammals than insects where it is limited by diffusion, permitting an increase in maximum body size. The torso in effect becomes a pressure vessel with limbs, with the ribs undergoing morphological changes including external dimensions, cortical thickness and bone density typical of a pressure vessel $(23,24)$.

\section{Lack of size efficiency}



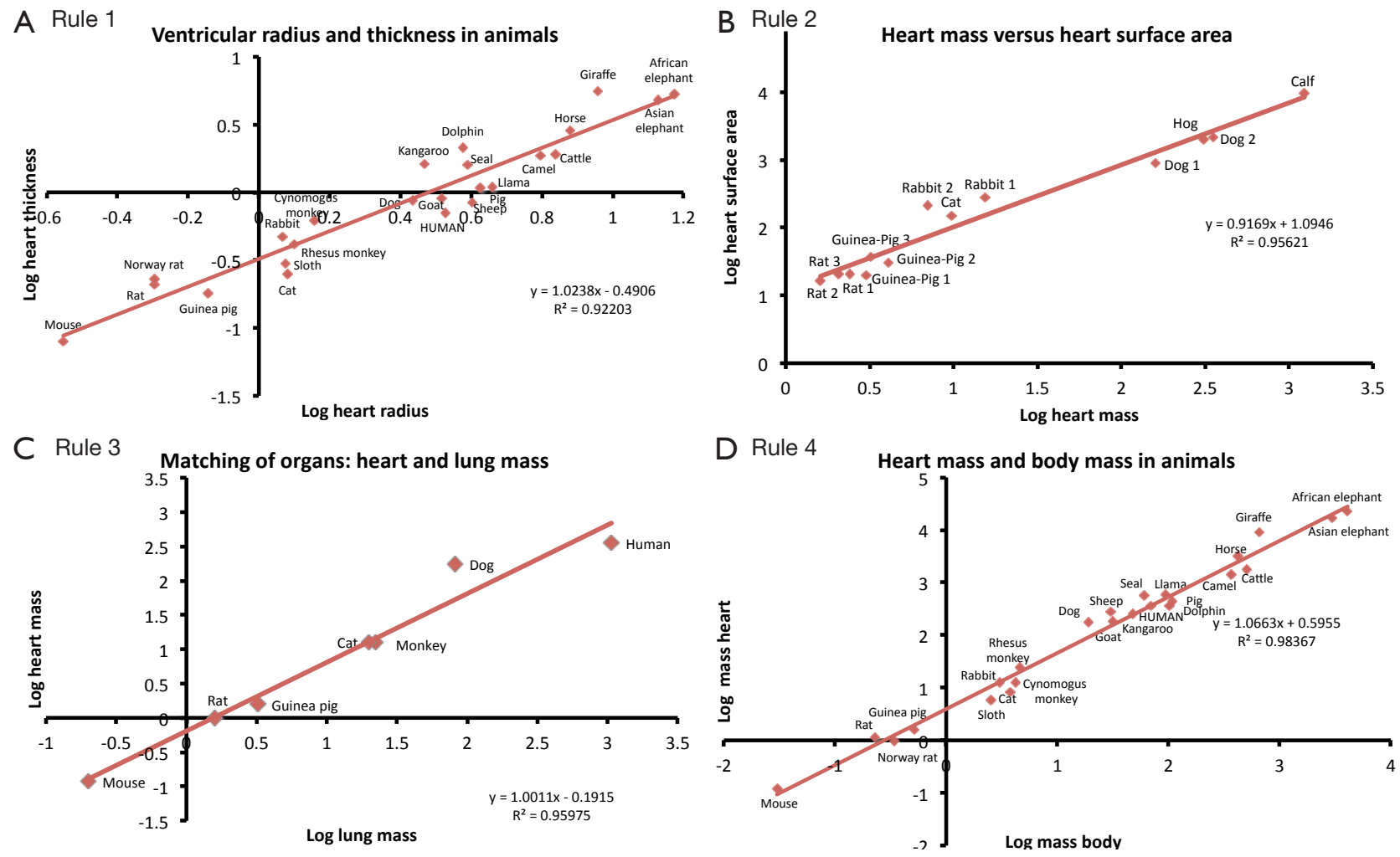

E Rule $5 \quad$ Lung volume and lung mass

F Rule $6 \quad$ Cardiac mass and pressure-volume product in animals
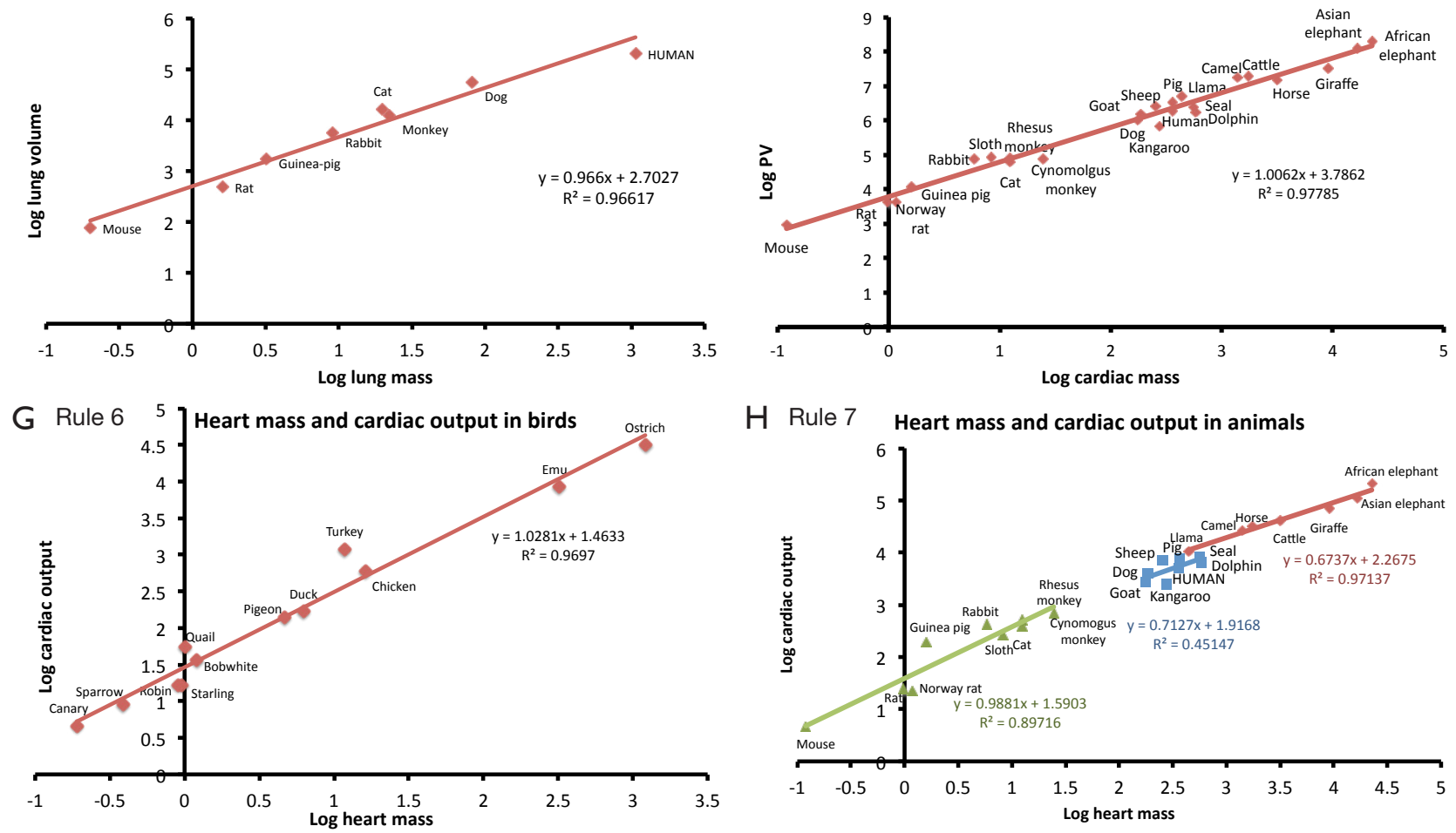

H Rule 7 Heart mass and cardiac output in animals

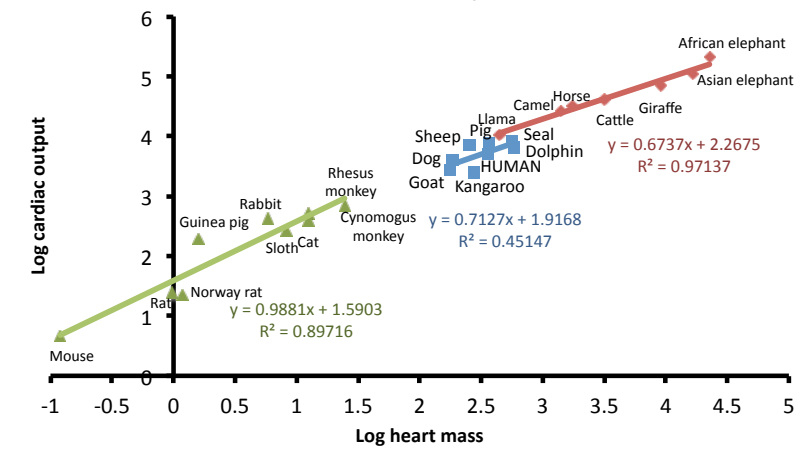

Figure 1 A set of seven physiological rules applied to pressure-based organs or organ systems showing isometry. In the case of the heart, increasing size leads to a reduction in cardiac output but not in pressurization energy, resulting in a reduction in cardiac efficiency, with cardiac output reaching the theoretical isometrical maximum in all birds but only in small mammals $<10 \mathrm{~kg}$. Data from Martin, Crosfill and Seymour (12,17,18). 

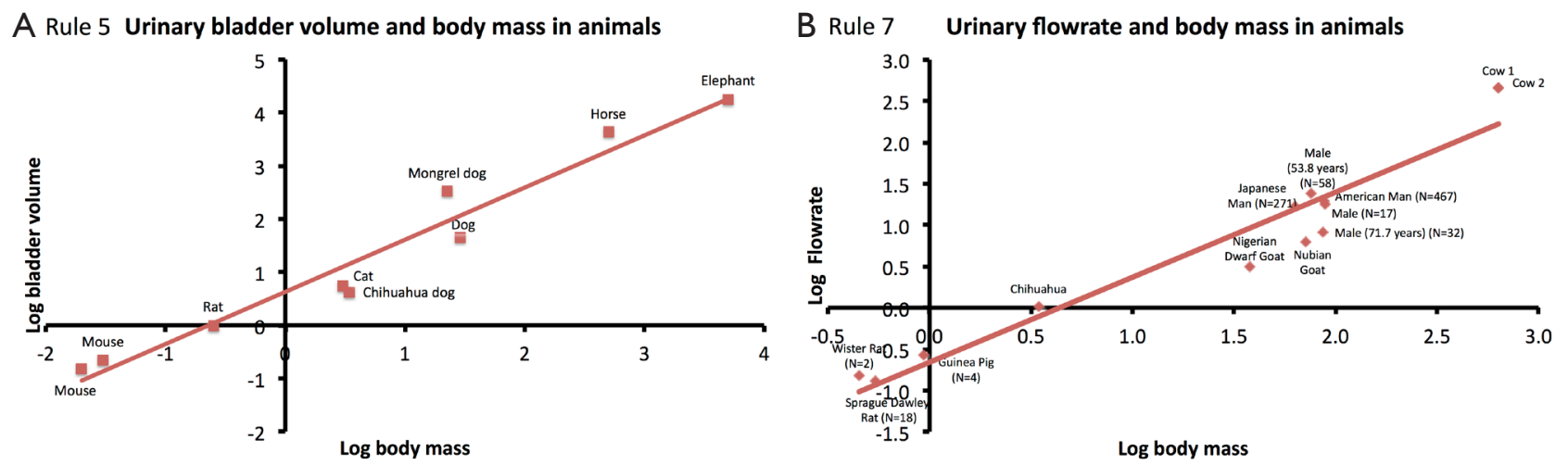

Figure 2 The bladder acts as a physiological pressure vessel with (A) bladder volume following Rule 5, $\alpha=0.98 r^{2}=0.96$, where $\alpha$ represents allometry and $r^{2}$ is the coefficient of determination, and (B) urinary flow rate observing Rule 7, $\alpha=1.03 r^{2}=0.93$. Since bladder volume and urinary flow-rate both scale isometrically, then urinary flow rate should be directly related to bladder volume, suggesting that micturition time is a constant. Data from Yang (20).

The mass of a pressure-based organ (e.g., lung) is also isometrically proportional to its contents (Rule 5) and also to its pressurization energy or work (Rule 6). Therefore the rate of change of pressurization, or work, is related to the change in volume over time, or tidal volume. In fact, tidal volume is related to body mass with a scaling exponent of 1.08 (18). Rule 5 holds for the heart's including endsystolic and end-diastolic volumes as pressure-based organ "content".

Assuming that pressurization energy is dissipated efficiently and in a simplification of the dynamic situation in a fractal environment (25), this work suggests that work output is proportional to pressure vessel mass (Rule 7). Figure 2 shows that urinary flow-rate is isometrically related to bladder mass, with a similar relationship between urinary volume and mass. Since bladder volume and urinary flow-rate both scale isometrically, then urinary flow rate should be proportionally related to bladder volume, implying that micturition time must be a constant, thus explaining why the time to micturate in mammals is fairly constant at 21 seconds (20).

\section{Lack of efficiency in pressurization energy dissipation in thick walled pressure vessels}

According to Rule 7, one would expect that cardiac output is isometrically related to heart mass. Based on experimental data, this is true for birds (18). Of note, birds are relatively lightweight, limited by the requirement of flight, however this relationship also holds for heavy flightless birds like the ostrich and emu. On the other hand, cardiac output in mammals is only isometric for animals with a weight up to $10 \mathrm{~kg}$. Cardiac output allometry drops to 0.71 in mediumsized 10-100 kg mammals like the human, and further decreases to 0.67 in large mammals $>100 \mathrm{~kg}$. Cardiac output is the multiple of heart rate and stroke volume; but heart rate carries a near zero allometry, whilst stroke volume mirrors cardiac output (26).

\section{Limitation to Cope's rule}

In effect, increasing mammal size leads to a reduction in cardiac output, but not in pressurization energy, thus resulting in a reduction in the cardiac efficiency. This is important as it acts to limit body size and thus breaks Cope's rule [1887] that describes the widespread tendency of animal groups to evolve towards a larger physical size. This means that although large animals are advantaged in evolutionary terms since smaller animals are unlikely to eat larger ones, the size of the animal limits cardiac efficiency.

\section{Differing rates of beart and aortic scaling}

This loss in cardiac efficiency with increasing body mass can be explained by the fact that the heart is a thick walled pressure vessel and because aortic cross-section size scales up at a rate of $0.70-0.72$ (27), following the three-quarter allometry law $(28,29)$. The heart is therefore throttled by a relatively small aorta at large body size. To illustrate the size comparison, a human has a heart that weighs $0.25-0.35$ $\mathrm{kg}$ with an aortic diameter of $3 \mathrm{~cm}$, whilst in contrast, a 
Table 1 Allometric relationships in biological pressure-vessel organs

\begin{tabular}{|c|c|c|c|c|c|c|c|c|c|c|}
\hline Rule & Figure & Description & Data & Species & $\begin{array}{c}\text { Pearson } \\
\mathrm{R}^{2}\end{array}$ & $\begin{array}{l}\text { Pearson } \\
P \text { value }\end{array}$ & Allometry $\alpha$ & $\begin{array}{c}\text { Standard } \\
\text { error }\end{array}$ & $\begin{array}{c}95 \% \\
\text { confidence } \\
\text { interval }\end{array}$ & $\begin{array}{l}T \text {-test }{ }^{*} \mathrm{P} \text { va } \\
\text { significant } \\
\text { more than } \mathrm{C}\end{array}$ \\
\hline \multirow[t]{5}{*}{1} & \multicolumn{10}{|c|}{ Isometry between pressure vessel radius and wall thickness (Laplace's Law) } \\
\hline & & $\begin{array}{l}\text { Right ventricular } \\
\text { radius + thickness }\end{array}$ & Woods & Humans & 0.9612 & $<0.001$ & 1.0751 & 0.1080 & $0.775-1.375$ & 0.525 \\
\hline & & $\begin{array}{l}\text { Ventricular radius } \\
\text { + thickness }\end{array}$ & Martin & Mammals & 0.9819 & $<0.001$ & 0.9794 & 0.0401 & $0.891-1.068$ & 0.118 \\
\hline & \multirow[t]{2}{*}{$1 \mathrm{~A}$} & $\begin{array}{c}\text { Ventricular radius } \\
\text { + thickness }\end{array}$ & Seymour & Mammals & 0.9220 & $<0.001$ & 1.0238 & 0.0635 & $0.892-1.155$ & 0.711 \\
\hline & & $\begin{array}{c}\text { Ventricular radius } \\
+ \text { thickness }\end{array}$ & Seymour & Birds & 0.8733 & $<0.001$ & 0.9305 & 0.1121 & $0.681-1.180$ & 0.549 \\
\hline
\end{tabular}

2 Isometry between pressure vessel mass and surface area (pressure-based organ as shell)

$\begin{array}{llllllllll}\text { 1B } & \begin{array}{c}\text { Heart mass }+ \\ \text { surface area }\end{array} & \text { Martin } & \text { Mammals } & 0.9562 & <0.001 & 0.9169 & 0.0592 & 0.787-1.047 & 0.188\end{array}$

3 Isometry between pressure vessels in the same body (matched in size)

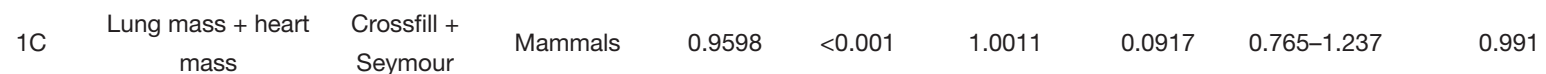

$4 \quad$ Isometry between body mass and pressure vessel mass (body scales as pressure-based organ)

$\begin{array}{ccccccccc}\text { 1D } & \text { Heart + body mass } & \text { Seymour } & \begin{array}{c}\text { Mammals }- \\ \text { giraffe }\end{array} & 0.9856 & <0.001 & 1.0520 & 0.0277 & 0.994-1.110 \\ \text { Heart + body mass } & \text { Seymour } & \text { Birds } & 0.9548 & <0.001 & 0.9038 & 0.0622 & 0.765-1.042 & 0.153 \\ \text { Heart + body mass } & \text { Martin } & \text { Mammals } & 0.9473 & <0.001 & 0.9439 & 0.0671 & 0.796-1.092 & 0.449 \\ \text { Lung }+ \text { body mass } & \text { Crosfill } & \text { Mammals } & 0.9794 & <0.001 & 1.0884 & 0.0645 & 0.931-1.246 & 0.219\end{array}$

5 Isometry between pressure vessel mass and volume of contents (no "efficiency of size")

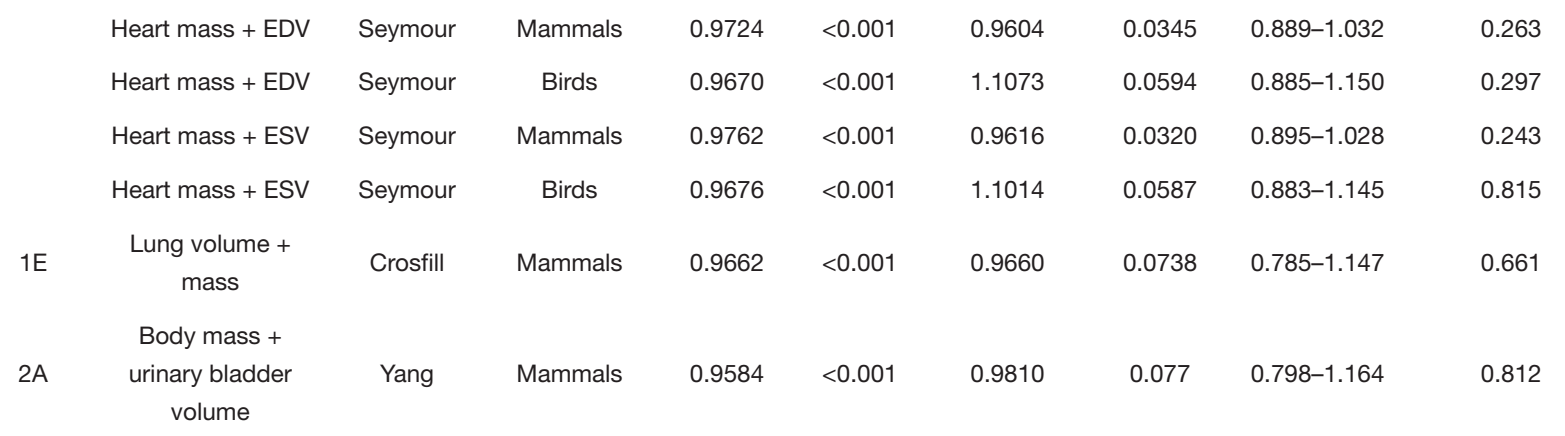

Table 1 (continued) 
Table 1 (continued)

\begin{tabular}{|c|c|c|c|c|c|c|c|c|c|c|}
\hline Rule & Figure & Description & Data & Species & $\begin{array}{c}\text { Pearson } \\
\mathrm{R}^{2}\end{array}$ & $\begin{array}{l}\text { Pearson } \\
P \text { value }\end{array}$ & Allometry $\alpha$ & $\begin{array}{c}\text { Standard } \\
\text { error }\end{array}$ & $\begin{array}{c}95 \% \\
\text { confidence } \\
\text { interval }\end{array}$ & $\begin{array}{l}T \text {-test }{ }^{*} P \text { value } \\
\text { significant if } \\
\text { more than } 0.05\end{array}$ \\
\hline \multirow[t]{4}{*}{6} & \multicolumn{10}{|c|}{ Isometry between pressure vessel mass and pressurization energy (efficiency in generating energy) } \\
\hline & \multirow[t]{3}{*}{$1 \mathrm{~F}$} & $\begin{array}{c}\text { Heart mass + } \\
\text { Systolic BP*EDV }\end{array}$ & Seymour & Mammals & 0.9779 & $<0.001$ & 1.0062 & 0.0323 & $0.939-1.073$ & 0.850 \\
\hline & & $\begin{array}{c}\text { Heart mass + } \\
\text { Systolic BP*ESV }\end{array}$ & Seymour & Mammals & 0.9807 & $<0.001$ & 1.0074 & 0.0301 & $0.945-1.070$ & 0.808 \\
\hline & & $\begin{array}{c}\text { Heart mass + } \\
\text { Systolic BP*ESV }\end{array}$ & Seymour & Birds & 0.9691 & $<0.001$ & 1.0327 & 0.0583 & $0.903-1.163$ & 0.587 \\
\hline \multirow{5}{*}{7} & \multirow[t]{2}{*}{$1 \mathrm{G}$} & Heart mass $+\mathrm{CO}$ & Seymour & Birds & 0.9697 & $<0.001$ & 1.0282 & 0.0574 & $0.900-1.156$ & 0.634 \\
\hline & & Heart mass $+\mathrm{CO}$ & Seymour & Mammals & 0.9741 & $<0.001$ & 0.8409 & 0.0293 & $0.780-0.902$ & $<0.001$ \\
\hline & $1 \mathrm{H}$ & Heart mass $+\mathrm{CO}$ & Seymour & $\begin{array}{c}\text { Large } \\
\text { mammals }\end{array}$ & 0.9714 & $<0.001$ & 0.6737 & 0.0517 & $0.541-0.807$ & $<0.001$ \\
\hline & $1 \mathrm{H}$ & Heart mass $+\mathrm{CO}$ & Seymour & $\begin{array}{l}\text { Medium } \\
\text { mammals }\end{array}$ & 0.4515 & $<0.001$ & 0.7127 & 0.3207 & $0.000-1.498$ & 0.405 \\
\hline & $1 \mathrm{H}$ & Heart mass $+\mathrm{CO}$ & Seymour & $\begin{array}{c}\text { Small } \\
\text { mammals }\end{array}$ & 0.8972 & $<0.001$ & 0.9881 & 0.1264 & $0.689-1.287$ & 0.927 \\
\hline
\end{tabular}

Results of allometric relationships in physiological pressure vessels showing statistical significant concordance with predicted isometric scaling, apart from heart mass in mammals, due to scaling mismatch between cardiac output and aortic size. *, two-tailed $t$-test was used to assess the statistical difference between the notional expected allometry of 1.0 determined by pressure vessels physics and actual measured allometry, using the null hypothesis $\mathrm{H} 1 \neq 1$, so statistical significance occurs if $P>0.05$ if the allometric value is significantly different from $1(H 1: \alpha \neq 1)$. $R^{2}=$ coefficient of determination, $\alpha=$ scaling exponent. CO, cardiac output; EDV, end-diastolic volume; ESV, end-systolic volume.

blue whale has a heart weighing about $450 \mathrm{~kg}$ but an aortic diameter of only $23 \mathrm{~cm}$. Thus, whilst the blue whale's heart mass is about one thousand three hundred times that of the human, the aortic diameter is only eight times larger.

This paper has used a set of rules based on the physics of pressure vessels to show, through the concepts of symmorphosis and allometry in pressure-based organs like the heart, the economy of biomechanical design. The fact that different animals independently reach similar physical design constraints suggests that the response occurs at the tissue level with optimisation of muscle cellular function (4).

This work may also explain a number of disorders such as cardiac dysfunction in athletes. For example, the mismatch between cardiac and aortic sizing suggests that athletes will suffer an increasing outflow obstruction morphologically similar to aortic stenosis during heavy exercise. This may explain why chamber dilatation (30), myocardial microfibrosis (31) and exercise-induced troponin elevation (32) occur in athletes' hearts. Furthermore heavy exercise is associated with a worse prognosis than mild or moderate exercise $(33,34)$, probably due to backpressure effects from the relatively small aortic sizing. It also explains why a small valve size causing patient-prosthesis mismatch in aortic valve replacement results in increased mortality since a small obstructive prosthetic valve would further throttle cardiac efficiency $(35,36)$.

These physiological rules may also give a better insight into the biomechanics related to hollow organs such as the heart and bladder, such as the design of artificial body parts like artificial hearts. They may act as a guide to volume of contents to organ mass ratio during surgical reconstruction e.g., artificial urinary bladders or bladder size augmentation. 
Before concluding, it is important to highlight that the work presented here is elegantly supported by independently published data, and does not contradict current physiological theories but rather acts as a framework explaining the basis of isometric scaling and physiological characteristics in several different pressure-based hollow organs or organ systems. In contrast, blood vessels act as a distribution network (9) and do not follow the rules of pressure-based organs.

\section{Conclusions}

There appears to be an excellent degree of functionality and efficiency in the design of pressure vessels in the body, a feature replicated across species in the mammal and bird kingdoms, such that the whole body scales like a pressure vessel. Pressure-based organs like the heart, lungs and bladder in a genetically controlled space of a large number of mammalian and avian species follow rules based on the physics of pressure vessels. In the case of the heart, the relative negative allometry of aortic dimensions compared to the isometric cardiac sizing leads to a relative reduction in cardiac output versus pressurization energy, resulting in a reduced cardiac output efficiency of $71 \%$ in humans compared to small mammals and birds.

\section{Acknowledgements}

The authors would like to thank the University of Malta for partly funding this research and acknowledge support by members of the Auxetic Research Working Group at the University of Malta.

\section{Footnote}

Conflicts of Interest: The authors have no conflicts of interest to declare.

Ethical Statement: All results reported in this study are based on data from referenced work and the authors did not seek ethics approval since no experiments were carried out for this study and no participants were enlisted.

\section{References}

1. Taylor CR, Weibel ER. Design of the mammalian respiratory system. I. Problem and strategy. Respir Physiol 1981;44:1-10.

2. Elzinga $G$, Westerhof N. Matching between ventricle and arterial load. An evolutionary process. Circ Res 1991;68:1495-500.

3. Calder WA. Size, function, and life history. Cambridge, Mass: Harvard Univ. Press, 1984.

4. Weibel ER, Taylor CR, Hoppeler H. The concept of symmorphosis: a testable hypothesis of structure-function relationship. Proc Natl Acad Sci U S A 1991;88:10357-61.

5. Kleiber M. Body size and metabolic rate. Physiol Rev 1947;27:511-41.

6. Pokras MA, Karas AM, Kirkwood JA, et al. An introduction to allometry scaling and its uses in raptor medicine in Raptor biomedicine. In Redig PT, Cooper JE, Remple D. editors: Raptor biomedicine. Minneapolis, MN: Minnesota Univ. Press, 1993:211-24.

7. Cohen JE, Xu M, Schuster WS. Allometric scaling of population variance with mean body size is predicted from Taylor's law and density-mass allometry. Proc Natl Acad Sci 2012;109: 15829-34.

8. Shingleton A. Allometry: the study of biological scaling. Nat Educ Knowl 2010;3:2.

9. Harrison JF. Evolvability and nonevolvability of allometric slopes. Proc Natl Acad Sci U S A 2015;112:13426-7.

10. West GB, Brown JH, Enquist BJ. A general model for the origin of allometric scaling laws in biology. Science 1997;276:122-6.

11. Savage VM, Deeds EJ, Fontana W. Sizing up allometric scaling theory. PLoS Comput Biol 2008;4:e1000171.

12. Martin RR, Haines H. Application of Laplace's law to mammalian hearts. Comp Biochem Physiol 1970;34:959-62.

13. Pender DJ. A model analysis of static stress in the vestibular membranes. Theor Biol Med Model 2009;6:19.

14. Langlade NB, Feng X, Dransfield T, et al. Evolution through genetically controlled allometry space. Proc Natl Acad Sci U S A 2005;102:10221-6.

15. Young WC, Budynas RG. Roark's formulas for stress and strain. New York: McGraw-Hill, 2012.

16. Woods RH. A Few Applications of a Physical Theorem to Membranes in the Human Body in a State of Tension. J Anat Physiol 1892;26:362-70.

17. Crosfill ML, Widdicombe JG. Physical characteristics of the chest and lungs and the work of breathing in different mammalian species. J Physiol 1961;158:1-14.

18. Seymour RS, Blaylock AJ. The principle of Laplace and scaling of ventricular wall stress and blood pressure in mammals and birds. Physiol Biochem Zool 2000;73:389-405.

19. Murray-Lyon RM. The relation between body weight and arterial cross-section. J Exp Biol 1930;7:221-34.

20. Yang PJ, Pham JC, Choo J, et al. Law of urination: all 
mammals empty their bladders over the same duration. arXiv Prepr. arXiv1310.3737 2013;405:4-5.

21. Galilei G. Discorsi e dimostrazioni matematiche intorno a due nuove scienze attinenti la meccanica e i movimenti locali. Simeoni Arti Grafiche, Verona, 2011.

22. Gehr P, Mwangi DK, Ammann A, et al. Design of the mammalian respiratory system. V. Scaling morphometric pulmonary diffusing capacity to body mass: Wild and domestic mammals. Respir Physiol 1981;44:61-86.

23. Casha AR, Camilleri L, Manché A, et al. External rib structure can be predicted using mathematical models: An anatomical study with application to understanding fractures and intercostal muscle function. Clin Anat 2015;28:512-9.

24. Casha AR, Camilleri L, Manché A, et al. Internal rib structure can be predicted using mathematical models: an anatomic study comparing the chest to a shell dome with application to understanding fractures. Clin Anat 2015;28:1008-16.

25. Vlad MO, Morán F, Popa VT, et al. Functional, fractal nonlinear response with application to rate processes with memory, allometry, and population genetics. Proc Natl Acad Sci U S A 2007;104: 4798-803.

26. Li JK. Comparative cardiac mechanics: Laplace's law. J Theor Biol 1986;118:339-43.

27. Dreyer G, Ray W, Walker EW. The size of the aorta in warm-blooded mammals and its relationship to the body weight and to the surface area expressed in a formula. Proc R Soc B 1912;86:39-56.

28. West GB, Enquist BJ, Brown JH. The fourth dimension of life: fractal geometry and allometric scaling of organisms. Science 1999;284:1677-9.

29. Banavar JR, Moses ME, Brown JH, et al. A general basis for quarter-power scaling in animals. Proc Natl Acad Sci U S A 2010;107:15816-20.

30. Cavallaro V, Petretta M, Betocchi S, et al. Effects of sustained training on left ventricular structure and function in top level rowers. Eur Heart J 1993;14:898-903.

31. Waterhouse DF, Ismail TF, Prasad SK, et al. Imaging focal and interstitial fibrosis with cardiovascular magnetic resonance in athletes with left ventricular hypertrophy: implications for sporting participation. Br J Sports Med 2012;46:i69-i77.

32. Sharma S, Merghani A, Mont L. Exercise and the heart: The good, the bad, and the ugly. Eur Heart J 2015;36:1445-53.

33. O'Keefe JH, Patil HR, Lavie CJ, et al. Potential adverse cardiovascular effects from excessive endurance exercise. Mayo Clin Proc 2012;87:587-95.

34. Corrado D, Schmied C, Basso C, et al. Risk of sports: Do we need a pre-participation screening for competitive and leisure athletes? Eur Heart J 2011;32:934-44.

35. Shahzeb KM, Imran BF, Asadullah K, et al. Prosthesispatient mismatch causes a significantly increased risk of operative mortality in aortic valve replacement. Heart Surg Forum 2014;17:E127-31.

36. Rao V, Jamieson WR, Ivanov J, et al. Prosthesis-patient mismatch affects survival after aortic valve replacement. Circulation 2000;102:III5-9.
Cite this article as: Casha $\mathrm{AR}$, Camilleri L, Manché A, Gatt R, Gauci M, Camilleri-Podesta MT, Grima JN, Scarci M, Chetcuti S. Physiological rules for the heart, lungs and other pressure-based organs. J Thorac Dis 2017;9(10):3793-3801. doi:10.21037/jtd.2017.09.86 